\title{
Formation of Digital Competencies in the Head of an Educational Organization
}

\author{
Alexander Zhigadlo ${ }^{1, a^{*}}$, Natalia Rybakova ${ }^{1}$ \\ 1 Siberian State Automobile and Road University (SibADI), 644080, 5 Mira ave., Omsk, Russia \\ akaf ip@mail.ru \\ ${ }^{*}$ Corresponding author
}

Keywords: digital competence, manager, corporate information environment, information technology

\begin{abstract}
The paper focuses on the issues of the formation of digital competence of a modern leader in the management of educational organizations. There are three main components of digital decision-making technologies, between which there is a close relationship: people, processes, and data. All these three components are carefully considered in the paper.
\end{abstract}

\section{Introduction}

The relevance of using digital technologies in the life of educational institutions is not in doubt, since due to the globalization of the education market, a new set of requirements for the national education system is being formed.

One of the main requirements is the ability to work in a competitive and rapidly changing market of educational services. This ability can be provided at universities with a process-oriented management structure and automated (and therefore managed) business processes.

\section{Methodology}

In the study of theoretical and methodological conditions for the effective management of a modern university, relying on the research of Yu. I. Shcherbakova, it can be argued that the primary task is to conduct a system analysis of management problems facing modern higher education, and in general, to specific universities [11].

The formulated problems need to be classified and defined typical solutions. The practice of applying digital technologies in modern universities implies, first of all, an analysis of the directions of development of digital technologies in the field of higher education.

\section{Study}

Without a unified strategy for the development of digital technologies that is consistent with the business goals of the university, it is difficult to hope for the creation of an effective model for managing both the educational process and the university as a whole [9].

The transition to a two-level learning model, the Unified State Examination, changes in funding conditions, the introduction of a point-rating system for assessing performance, the implementation of the Federal State Education Standard of Professional Education directly or indirectly affect how digital technology should be applied at a university.

In addition, the large-scale use of digital teaching materials, including multimedia presentation, wireless technologies, presentation equipment, network technologies for access to resources, also affects the infrastructure of information technologies at a university and services of a university corporate information environment [1].

How can one determine the main tasks focusing on the effectiveness of solutions in a university, which is directly related to the use of digital technologies? If one does not use professional technical terminology, the answer is: "Digital technologies make it possible to most effectively organize activities of people 
(processes) and access to digital data."

Based on this, in any higher education institution, there are three main components of digital decisionmaking technologies, between which there is a close relationship: people, processes and data. From the point of view of management: how well the processes are solved and organized, the connection between people and data is ensured, the successful activity of the university depends in many ways [5].

A full-fledged corporate information environment of a higher educational institution will allow to manage knowledge, which ensures the development of innovations, an increase in labor productivity (the time required to find the right solution in management and the volume of work performed is reduced), and staff competence.

Using the concept of a unified corporate information environment of I. L. Chudinov, the unified information environment of a university will be understood as a system of technical, informational tools, and management decisions that provide:

- unambiguous presentation of information about objects of the subject area, focused on information support of the processes of functioning and development of a university in all areas of activity (management decisions, educational technologies, research projects, and innovative areas, etc.);

- integration into a single information model of the university of various types of information existing in the university;

- integrated, authorized use of information by various software modules, as well as students and staff of the university [10].

In our case, one can consider digitization of a university as a process of transition to a state of corporate information environment in which users get access to high-quality information, and the decisions in the field of digital technologies are so interwoven into the main business processes of the university that staff and students can no longer without services provided by the digital educational environment [4]. At the same time, official duties are performed by staff with greater efficiency, and student training is of better quality, which makes investments in information technology economically viable.

As you know, the profession of a manager is very specific. This specificity lies in the fact that the manager must perform a number of a wide variety of functions, ranging from personnel management to management processes in the organization. In our opinion, it is organization management that is the defining function in the activity of a modern manager. Thus, we can conclude that a specialist in the field of management should have a very universal knowledge, skills, and competencies that he needs in order to successfully perform his/her functional duties.

Professional competence of the head of an educational organization is the most important criterion for the quality of his managerial activities and is understood as the manager's ability and readiness for management based on professionally significant and personal qualities [6;8].

In this regard, at present, one of the most important resources is special knowledge and skills in the field of digital technologies, which ensure the personal and professional development of a modern leader.

Recently, the concept of "digital literacy" has become more and more popular. In it, on the one hand, researchers are trying to combine all types of literacy associated with the use of information and communication technologies. On the other, they attempt to highlight the types of competencies that are needed in the modern world due to the high level of access to the Internet.

What is digital competence? Analysis of the existing definitions shows that the concept of digital competence is one of the rapidly developing, changes are constantly being made in accordance with the development of modern information and communication technologies.

Most of the authors include in the concept of digital competence abilities and skills to effectively use digital technologies in everyday life, abilities and skills of critical assessment of technologies, motivation to participate in digital culture, as well as technical skills most often associated with computer literacy [2;3].

Considering digital competence as a complex phenomenon that today defines human life in different areas of the information community, we, considering this category from the point of view of management, 
include in it, respectively, four types of competence:

1. Information and media competence: knowledge, skills, motivation and responsibility related to searching, understanding, organizing, archiving of digital information and its critical thinking, as well as the creation of information objects using digital resources (text, graphic, audio and video);

2. Communicative competence: knowledge, skills, motivation, and responsibility necessary for various forms of communication (email, chat rooms, blogs, forums, social networks, etc.) and with different goals;

3. Technical competence: knowledge, skills, motivation and responsibility, allowing efficient and safe use of hardware and software for solving various tasks, including the use of computer networks, cloud services, etc.;

4. Consumer competence: knowledge, skills, motivation, and responsibility, allowing to solve various everyday tasks associated with specific life situations with the help of digital devices and the Internet [7].

As well as the phenomenon of digital competence, in general, each of the competencies included in its composition has components related to motivation and responsibility.

The motivational component involves the formation of a meaningful need for digital competence, as the basis of adequate digital activity, complementing human life in the modern era.

The responsibility component includes, in addition to all the above, competences in online security: skills and abilities to ensure security when working on the Internet with information, in the process of online communications, in solving various tasks related to consumption through the Internet, as well as the ability to provide technical security in the implementation all these actions.

We believe that the leader who, in the conditions of a changing market and the unstable conditions of the social environment, finds right solutions and advances his educational organization, will surely gain credibility and receive the best reward. After all, an effective leader is someone who would lead his team to success, develops effective management techniques and skills that help him in his work and in life.

Thus, among the key competencies of a modern head of an educational institution we include:

- An ability to work with the goals and values of their educational organization;

- An ability for effective external and internal communications;

- An ability to efficiently and safely use hardware and software for solving various tasks in managing an organization;

- An ability to accurately select key employees of the organization and use in their work the greatest strengths [11].

An analysis of research on the issue under consideration allowed to conclude that the formation of the digital competence of a modern manager provides:

- Effective management of an organizational structure and staff of the university;

- Application of an electronic document management system for all document-oriented processes;

- Control of executive discipline;

- Planning and reporting on various activities.

\section{Conclusion}

The development of innovations at a university (and digital technologies are the basis of innovations in the management and organization of the educational process) is the key to solving the problem of ensuring the high competitiveness of the university.

To a large extent, the success achieved in this direction is due to the fact that the university team trusts the decisions that are made by the university administration and are implemented by the IT service together with the 
university staff. Human factor is of great importance for achieving the goal.

In organizing their work, we follow simple principles: to be successful in your career, you need to take on what you know how to do professionally, build priorities based on understanding business perspectives, be consistent and not afraid of difficulties, and have a team of like-minded people.

\section{References}

[1] Wagner, Yu. B. (2011). Improving the university management system based on the process approach and automating the management of business processes: Dis. ... Cand. Economy of Sciences. Moscow, Russia: MSU.

[2] Granichina, O. A. (2014). Quality control of the educational process in the context of university management: Dis. ... Dr. Ped. Sciences. St. Petersburg: RGPU name. A. I. Herzen.

[3] Kryukov, V. V., Shahgeldyan, K. I. (2014). The development of the information infrastructure of the university for solving management problems. University Management, 4, pp. 67-77.

[4] Morozov, A. V. (2018). Management in the system of modern education (psychological and pedagogical aspect). Bulletin of the Faculty of Management SPbGEU, 3, pp. 237-242.

[5] Morozov, A. V. (2016). Features of higher education in modern conditions. Education Management: Theory and Practice, 2(22), pp. 90-106.

[6] Morozov, A. V. (2017). Features of management activities of the modern head of the educational organization. Moscow, Russia: FSBI "IUO RAO".

[7] Reznik, S. D., Sazykina, O. A. (2008). New activity priorities and modeling the qualities of higher education personnel. University Management: Practice and Analysis, 6, pp. 47-51.

[8] Fedorchuk, Yu. M., Neustroev, S. S., Polyaninova, Yu. V., Chekulaeva, Yu. A., Ilina, V. S., Bazhilina, A. V., Komarova, M. V. (2017). The concept of professional formation and development of the head of an educational institution in the context of the innovative socio-economic development of the Russian Federation. Scientific Notes IUO RAO, 3(63), pp. 100-114.

[9] Fedorchuk, Yu. M., Neustroev, S. S., Chekulaeva, Yu. A., Polyaninova, Yu. V., (2017). Effective practices and innovative models of professional development of the head of an educational organization. Moscow, Russia: FSBI "IUO RAO".

[10] Chudinov, I. L. (2005). The concept of a unified information environment and the experience of its implementation in the Tomsk Polytechnic University. In IT innovations in education. Materials AllRussia Scientific-Practical Conf. (Petrozavodsk, June 27-30, 2005). Petrozavodsk, Russia: PSU.

[11] Shcherbakov, Yu. I. (2010). Management activities in modern educational institutions. In Independent work of students in the structure of modern vocational education: a collection of scientific articles. Moscow, Russia: MPGU. 